\title{
A spectrum of epididymis and vas deferens anomalies among children with cryptorchidism: a retrospective multi-center study
}

Sarah Magdy Abdelmohsen ${ }^{1,2^{*}}$ (D), Mohamed Abdelkader Osman ${ }^{3}$, Mohammed Hamada Takrouney ${ }^{3}$, Mohamed El Debeiky ${ }^{4}$, Ahmed Badawe G. Hassan ${ }^{5}$, Mohamed Mahmoud Abd El-Aleem Shalaby ${ }^{6}$ and Mohamed A. Baky Fahmy ${ }^{7}$

\begin{abstract}
Background: Vasoepididymal anomalies are not rare among children with cryptorchidism. They may affect fertility following orchiopexy. Herein, we describe the cases of abnormalities of the vas deferens and epididymis in children undergoing orchidopexy for cryptorchidism. Data were collected retrospectively from six centers providing care for patients with undescended testicles from September 2017 to February 2019. All patients whose congenital anomalies of the epididymis or vas deferens were discovered incidentally during operative intervention for cryptorchidism and where photographs of the anomalies were taken were included.

Results: The total incidence of congenital anomalies on the 467 testicles which had operations was 13.2\%. Congenital epididymal and vas deferens anomalies were more common on the left side than the right side in patients with cryptorchidism $(P=0.038)$. Attachment anomalies between the epididymis and testis were the most common epididymal anomaly (36.3\%), while a vanished vas deferens was the most frequent vas deferens anomaly (18\%). Three patients had absent vas deferens, two had curled vas deferens, two had vas deferens separated from the epididymis, and one had a duplicated vas deferens. Three patients had an epididymal cyst, one had an enlarged appendix of the epididymis, and one had epididymal agenesis.

Conclusion: Attention must be paid during any surgery on an undescended testicle as an anomaly of the vas deferens could lead to unexpected complications. Anomalies of the vas deferens or epididymis that present in cases of cryptorchidism occur mostly on the left side.
\end{abstract}

Keywords: Epididymis, Undescended testis, Epididymal cyst, Vanished testis, Curled vas deferens, Duplicated vas deferens

\footnotetext{
*Correspondence: Sara.magdy@aswu.edu.eg; sosoramily@yahoo.com

${ }^{1}$ Faculty of Medicine, Pediatric Surgery Unit, Aswan University Hospital, Aswan, Egypt

${ }^{2}$ Haddaek El Kobba, 27 Diab Fahmiy Str., P.O. Box 11331, Cairo, Egypt

Full list of author information is available at the end of the article
}

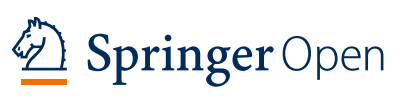

(c) The Author(s). 2021 Open Access This article is licensed under a Creative Commons Attribution 4.0 International License, which permits use, sharing, adaptation, distribution and reproduction in any medium or format, as long as you give appropriate credit to the original author(s) and the source, provide a link to the Creative Commons licence, and indicate if changes were made. The images or other third party material in this article are included in the article's Creative Commons licence, unless indicated otherwise in a credit line to the material. If material is not included in the article's Creative Commons licence and your intended use is not permitted by statutory regulation or exceeds the permitted use, you will need to obtain permission directly from the copyright holder. To view a copy of this licence, visit http://creativecommons.org/licenses/by/4.0/. 


\section{Background}

An undescended testicle, a common congenital anomaly affecting approximately $2 \%$ of male neonates, can be associated with a wide range of other congenital anomalies. These children, whether or not they undergo surgery, may have sequelae of poorly functioning testicles attributed to a wide spectrum of other congenital anomalies that can affect the testicle, epididymis, or vas deferens. These anomalies may be associated with infertility which may be improved in some cases with an early orchiopexy. Even with a normal contralateral testicle, there may be fertility problems attributed to associated anomalies of the vas deferens or epididymis.

While anomalies of the testis, epididymis, and vas deferens are found in $2 \%$ of normal male fetuses, epididymal anomalies are more common in cryptorchid testes [1]. However, their exact incidence is underestimated and it is unlikely that it can be done accurately, as operative records of testicular or scrotal surgery generally do not an elaborate detailed description of outcomes. Also, most descriptions of these anomalies are isolated case reports or are from selected populations and are therefore of limited statistical value [2].

Until 1971, there had been little effort for the structured or classification of epididymal and vasal anomalies associated with undescended testicles [2-4]. Although, we modify this classification by more detailed subdivision to epididymal and vasal anomalies and by adding few missing anomalies.

This paper intends to be a teaching resource with a visual catalog of 22 associated abnormalities of the epididymis and vas deferens observed in children undergoing orchidopexy for undescended testes.

\section{Methods}

We retrospectively collected data from patients with anomalies of the epididymis or vas deferens. These anomalies were discovered incidentally during operative intervention for cryptorchidism. A series of 430 patients with 467 testicles were analyzed from September 2017 to February 2019. All included cases had photographic documentation. This visual documentation was evaluated by the most senior staff.

All patients underwent surgery by one of seven experienced pediatric surgeons at six different Egyptian university hospitals. All patients underwent surgery with the same technique (open surgery for a palpable cryptorchid testicle or laparoscopic surgery for a non-palpable cryptorchid testicle).

All testes were fixed to the ipsilateral sub-dartos pouch. All epididymides and vasa deferentia were carefully examined, and any observed anomalies were recorded. Congenital anomalies of the epididymis were classified by our modified system detailed in Fig. 1 [1, 5, 6]. Anomalies of the vas deferens are listed in Table 1 [5]. Our modified classification system was referred from the classification system of Sanjeev and Morgentaler, 1997 [5].

Data, including the antenatal history, history of associated anomalies, location of the testicle, and results of a renal ultrasound, were obtained from the medical records. Patients without photographic documentation of the anomalies were excluded from the study.

\section{Consent for publication}

Written consent was obtained from all of the included patients' parents for operative intervention, but no consent was obtained for the publication of intra-operative pictures because they do not contain any personal details.

\section{Ethical approval and consent for participate}

It obtained by 1st author institute ethical commitment. Written informed consent was obtained from the parent and or legal guardian of every participant.

\section{Statistical analysis}

SPSS, version 17, was used to perform statistical analyses. The Pearson chi-square test was used for the comparative analysis of categorical variables. A $P$ value < 0.05 was considered significant.

\section{Results}

A total of 467 testes were observed in 430 patients, with 37 patients having bilateral undescended testes. Interventions performed included an open inguinal incision, laparoscopy, and combined inguinal incision and laparoscopy in 248, 190, and 29 testes, respectively.

Only 57 patients with congenital anomalies of the vas deferens or epididymis were discovered incidentally during the operative intervention for cryptorchidism. Of these 57 patients, only 22 had photographic reports and were included in this study. The total incidence rate for epididymal and vas deferens anomalies in this study was $13.2 \%$. None of the included patients had a history of maternal drug use or radiation exposure.

The patients ranged from 8 to 125 months (mean, 34 months) in age at the time of operation. Sixteen patients underwent surgery with a conventional open technique, 4 underwent surgery utilizing a laparoscopic technique, and 2 patients were managed with a combination of open and laparoscopic techniques. 

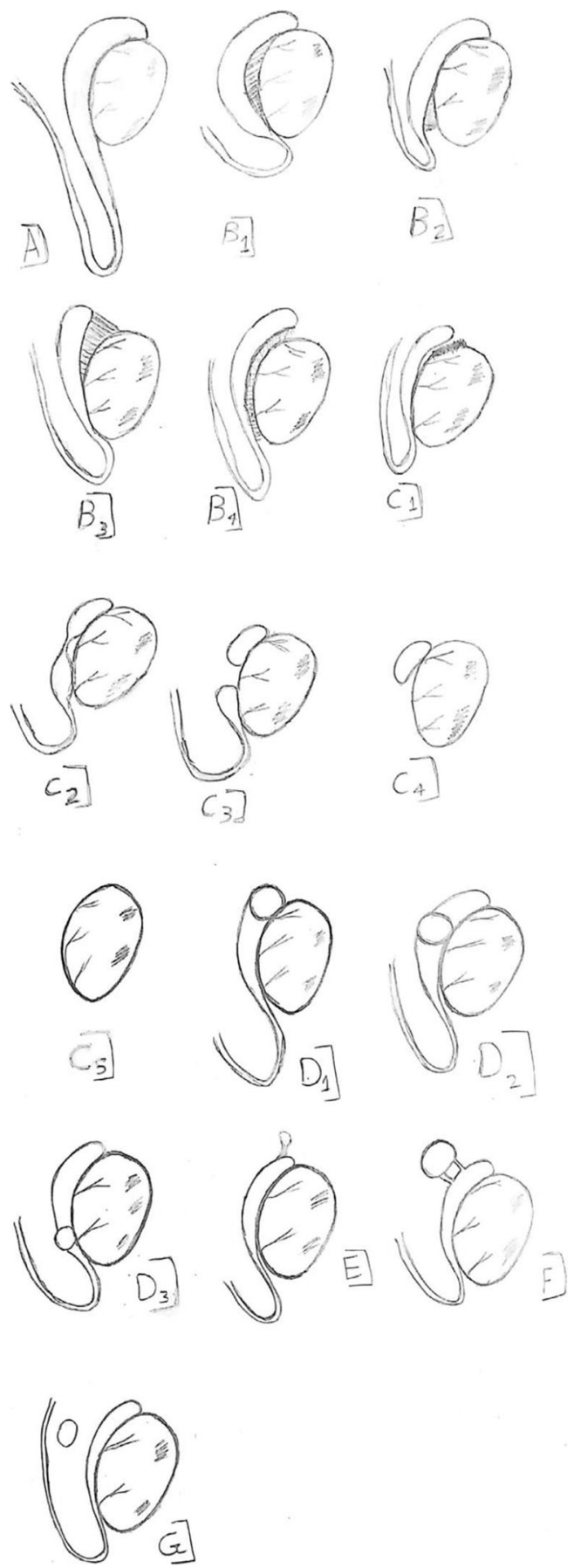

Fig. 1 Congenital anomalies of the epididymis [5]. A Elongated (looping) epididymis. B Anomalies of attachment to the testis [6]. B1 Attachment of caput and cauda (detached corpus). B2 Attachment of caput only. B3 Attachment of cauda only. B4 Complete separation of the testis and epididymis. $\mathbf{C}$ Epididymal anomalies of obliteration (agenesis) [1]. C1 Obliteration of the efferent ducts. C2 Obliteration of the epididymal body. C3 Epididymal body separated into two parts. C4 Agenesis of the distal half of the epididymis. C5 Complete epididymal agenesis. D Congenital epididymal cyst. D1 Caput cyst. D2 Corpus cyst. D3 Caudal cyst. E Enlargement stalk of the epididymal appendix. F Duplication. G Ectopia
Table 1 Anomalies of the vas deferens [5]

o Unilateral absence of vas deferens

o Congenital bilateral absence of vas deferens

o Ectopic vas deferens

o Duplication of vas deferens

o Diverticulum of vas deferens

o Segmental aplasia of vas deferens (skip vas)

o Crossed dystopia of the vas deferens

Table 2 shows a number of epididymal and vas deferens anomalies compared with the laterality of the undescended testicle. Congenital epididymal and vas deferens anomalies were more commonly found on the left than on the right side in patients with cryptorchidism $(P=$ 0.038 ,). There was no statistically significant difference between testicle location and epididymal anomalies $(P=$ 0.059, Table 3).

The different anomalies detected in the vas deferens and epididymis were listed in Table 4. Disconnection anomalies between the epididymis and testicle were the most common epididymal anomaly no. 8 (36.3\%), while a vanished vas deferens was the most frequent vas deferens anomaly no. 4 (18\%).

Table 5 lists the associated anomalies and syndromes in our patients.

\section{Discussion}

All types of vaso-epididymal anomalies are encountered with cryptorchidism. We found no statistically significant association between vas deferens and/or epididymal anomalies and the location of the undescended testicle $(P=0.059)$, although this was close to being significant. A unique aspect of this study was its reliance on photographic reports of the various anomalies. We correlated the perceived deficiencies with the numerous existing classification systems.

Table 2 Epididymis and vas deferens anomalies in cross tabulation with the laterality of the undescended testicle

Epididymis and vas deferens anomalies \& Undescended testis laterality cross tabulation

\begin{tabular}{|c|c|c|c|c|}
\hline \multirow[t]{2}{*}{ Count } & & \multicolumn{2}{|c|}{ Undescended testis } & \multirow[t]{2}{*}{ Total } \\
\hline & & $\begin{array}{l}\text { Right } \\
\text { undescended } \\
\text { testis }\end{array}$ & $\begin{array}{l}\text { left } \\
\text { undescended } \\
\text { testis }\end{array}$ & \\
\hline \multirow{2}{*}{$\begin{array}{l}\text { Epididymis and vas } \\
\text { deferens anomalies }\end{array}$} & Yes & 6 & 16 & 22 \\
\hline & No & 222 & 223 & 445 \\
\hline Total & & 228 & 239 & 467 \\
\hline
\end{tabular}

Chi-square test $=0.038, \mathrm{p}$ value for significance $<0.05$ 
Table 3 Congenital epididymal and vas deferens anomalies with level of undescended testicles Crosstabulation

\begin{tabular}{|c|c|c|c|c|}
\hline \multirow[t]{2}{*}{ Count } & & \multicolumn{2}{|c|}{ Level of undescended testicles } & \multirow[t]{2}{*}{ Total } \\
\hline & & $\begin{array}{l}\text { Law } \\
\text { undescended } \\
\text { testicles } \\
\text { (inguinal) }\end{array}$ & $\begin{array}{l}\text { High } \\
\text { undescended } \\
\text { testicles } \\
\text { (abdominal) }\end{array}$ & \\
\hline \multirow{2}{*}{$\begin{array}{l}\text { Congenital } \\
\text { epididymal and vas } \\
\text { deferens anomalies }\end{array}$} & Yes & 16 & 6 & 22 \\
\hline & No & 232 & 213 & 445 \\
\hline Total & & 248 & 219 & 467 \\
\hline
\end{tabular}

Pearson chi-square $=0.059$

A long, curled vas deferens was first reported in 1910 by Moschcowitz [9] and may be present in up to $20 \%$ of undescended testes located inside or proximal to the inguinal canal. This associated abnormality may be injured during orchidopexy [10]. Thomas and Day favored performing a detailed inspection of structures inferior to the lower pole of the testicle early on. This allowed for confirmation of the presence of a curled vas and enabled appropriate caution to be taken to avoid inadvertent transection during surgery.

Based on our experience, sometimes the vas deferens enters the inguinal ring, proceeds for a distance in the inguinal canal, and then returns to the abdominal testicle. Such cases are called a curled vas deferens and could be removed when a vanished testicle is determined during inguinal exploration without performing laparoscopic exploration (patients 1 and 2, Figs. 2 and 3a, malformation type A).

The partial or complete obstruction associated with anomalies of attachment between testicle and epididymis may lead to difficulties with sperm transport with

Table 4 Anomalies of the vas deferens and the epididymis detected in our study

\begin{tabular}{|c|c|c|c|c|}
\hline Case no. & Anomalies & No. & Fig. no. & Malformation type \\
\hline \multicolumn{5}{|c|}{ Anomalies of the epididymis } \\
\hline $1-2^{\mathrm{a}}$ & $\begin{array}{l}\text { A long curled vas deferens (looping epididymis). } \\
\text { Case no. } 2 \text { had also complete detached epididymis from testis. }\end{array}$ & 2 & 2 and $3 A$ & A \\
\hline 3 & Congenital enlarged appendix of the epididymis. & 1 & $3 \mathrm{~B}$ & $E$ \\
\hline $4-6$ & $\begin{array}{l}\text { A congenital epididymal cyst (caput and corpus). A case no. } 4 \text { had also detached } \\
\text { body of the epididymis from the testis. }\end{array}$ & 3 & 4 & D \\
\hline $7^{a}$ & $\begin{array}{l}\text { The epididymis is completely detached from the testis. } \\
\text { One case of repeated curled vas deferens. } \\
\text { One case of repeated duplication of the vas deferens }\end{array}$ & 3 & $\begin{array}{l}\text { 5A and 3A } \\
\text { (repeated) } \\
\text { and } \\
6 \\
\text { (repeated) }\end{array}$ & B4 \\
\hline $8^{b}$ & The caput and corpus of the epididymis is detached from the testis. & 1 & $5 B$ & B3 \\
\hline $9-11^{\prime \prime}$ & $\begin{array}{l}\text { The corpus of the epididymis is detached from the testis. } \\
\text { Case no. } 11 \text { had also congenital diaphragm. }\end{array}$ & 4 & $\begin{array}{l}4 \mathrm{~A} \text { (repeated) } \\
\text { and } \\
7 \text { and } 8\end{array}$ & B1 \\
\hline 12 & Complete epididymal agenesis & 1 & 9 & C5 \\
\hline \multicolumn{5}{|c|}{ Anomalies of the vas deferens } \\
\hline $13-15^{c}$ & Vanished proximal part of the vas deferens half an inch from the internal ring. & 3 & $10-11$ & Table $1[5]$ \\
\hline $16-18$ & Absence vas deferens. & 2 & $12-13$ & Table $1[5]$ \\
\hline 19 & $\begin{array}{l}\text { Congenital separated vas deferens. } \\
\text { One case of repeated curled vas deferens. }\end{array}$ & 2 & $\begin{array}{l}14 \\
\text { and } \\
3 \\
\text { (repeated) }\end{array}$ & d \\
\hline $20^{a}$ & $\begin{array}{l}\text { Duplication of the vas deferens. } \\
\text { Also, the epididymis is completely detached from the testis. }\end{array}$ & 1 & $6 \mathrm{~A}$ and $\mathrm{B}$ & $\begin{array}{l}\text { Table } 1[5] \\
\text { and } \\
\text { B4 }\end{array}$ \\
\hline $21^{5 ! !}$ & Vanished distal part of the right vas deferens [7]. & 1 & & Table $1[5]$ \\
\hline 22 & $\begin{array}{l}\text { Congenital union between right and left vasa deferentia in a case of crossed } \\
\text { testicular ectopia (crossed dystopia of the vas deferens) [8]. }\end{array}$ & 1 & & Table $1[5]$ \\
\hline
\end{tabular}

According to the classification system adopted in this study (Fig. 1):

a Patients 2, 7, and 20 had testes that were completely separated from the epididymis (Figs. 3a, 5a, and 6b, malformation type B4).

b Patient 8 had an epididymis attached at the caudal end only (Fig. 5b, malformation type B3), while patients 9,10 , and 11 " had an epididymis attached at the

caput and the cauda (detached corpus, Figs. 4a, 7, and 8, malformation type B1). However, patient 11 " had a congenital diaphragm

c 3 Patients had a congenitally absent proximal part of the left vas deferens (proximal aplasia) (patients 13, 14, and 15; Figs. 10 and 11, Table 1), and we previously reported a case of a congenitally absent distal part of the right vas deferens 5 !!

${ }^{d}$ We recommend adding this missing anomaly and modifying the classification system of the vas deferens (Table 1) [5] 
Table 5 Associated anomalies and syndrome detected with epididymal and vas deferens anomalies in cases of cryptorchidism

\begin{tabular}{ll}
\hline Associated anomalies and syndrome & Number \\
\hline Vanishing testis & 3 \\
Partial androgen insensitivity syndrome & 1 \\
Unilateral absent kidney & 1 \\
Cardiac anomalies ASD & 1 \\
\hline
\end{tabular}

subsequent impairment of fertility, despite early surgical correction of an undescended testicle. Also, an elongated epididymis may result in problems for sperm maturation, transportation, and infertility [11]. Patient 11 had a congenital diaphragm, and we, therefore, considered this a mild form of epididymal detachment (patient 11, Fig. 8, malformation type B). Qin, et al. in 2020 found a rate of disconnection between the epididymis and testicle of $21.4 \%$ [12]. The rate of disconnection anomalies in our study is $36.3 \%$ (patients 2, 4, 7, 8, 9, 10, and 11, Figs. 3a, 4a, 5, 6, 7 and 8 , malformation type B) (Table 4). While in Caterino, 2014, the rate of the only disconnection between the epididymis and testicle is $51.5 \%$ [13].

An enlarged appendix of the epididymis is a developmental remnant of the mesonephric (Wolffian) duct [14]. Normally, epididymal appendages are of no clinical significance, but when inflammation or torsion occurs, they can cause acute scrotal pain in children [15]. This is most commonly due to torsion because the stalk is long in $78 \%$ of cases [15]. This finding was not listed in the classification of epididymal anomalies, but we have added it to our modified classification system as type E. In this case, the surgeon did not remove the enlarged, stalked appendix of the epididymis; however, we recommend removal to avoid torsion (patient 3, Fig. 3b, malformation type E).

Embryological epididymal cysts represent blind-end efferent ducts that failed to fuse with the mesonephric duct during embryogenesis. They do not compromise fertility if other efferent ducts form normal unions with the epididymal tubules. However, in the case of obstructive azoospermia, these cysts may represent a reservoir for sperm aspiration [5]. This is an incidental finding in approximately $14.4 \%$ of asymptomatic boys. The incidence of cysts increased with age, with a total of $35.3 \%$ of boys older than 15 years having cysts. These cysts are clinically irrelevant, and no treatment is required in asymptomatic cases [16]. In our modified classification system, we classified the epididymal cyst according to its position in the epididymis (patients 4,5 , and 6, Fig. 4; malformation type D).

The diagnosis of a duplicated vas deferens can be made on physical examination, but it requires a high degree of clinical suspicion [5]. Additionally, caution is advised to avoid causing inadvertent injury to the vas deferens in patients with this anomaly. When present, this condition should not be forgotten during vasectomy operations (patient 20, Fig. 6, Table 1).

Four patients in our study had segmental vas deferens atresia. Proximal and distal were defined according to the direction of sperm movement from the epididymis (proximal) to the prostate (distal) [7] (patient 13,14, 15 and 21, Figs. 10 and 11, Tables 1 and 4).

We attributed this segmental atresia to a vascular accident occurring during an early phase of development when the arterial supply of the gonad and Wolffian duct originates from lateral branches of the dorsal aorta. However, during involution of the

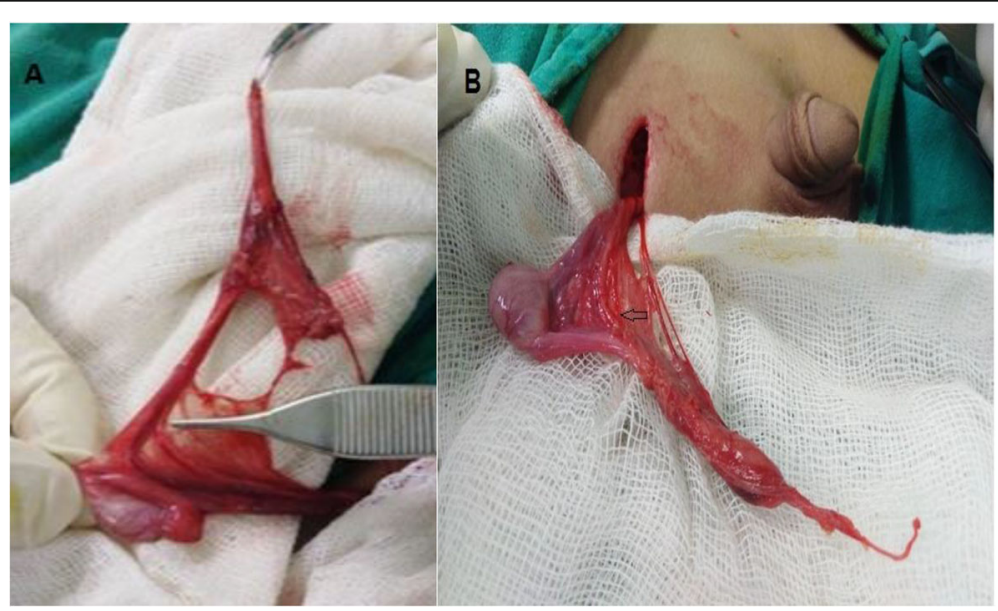

Fig. 2 a congenital long looping epididymis and looping vas deferens. b Another view 


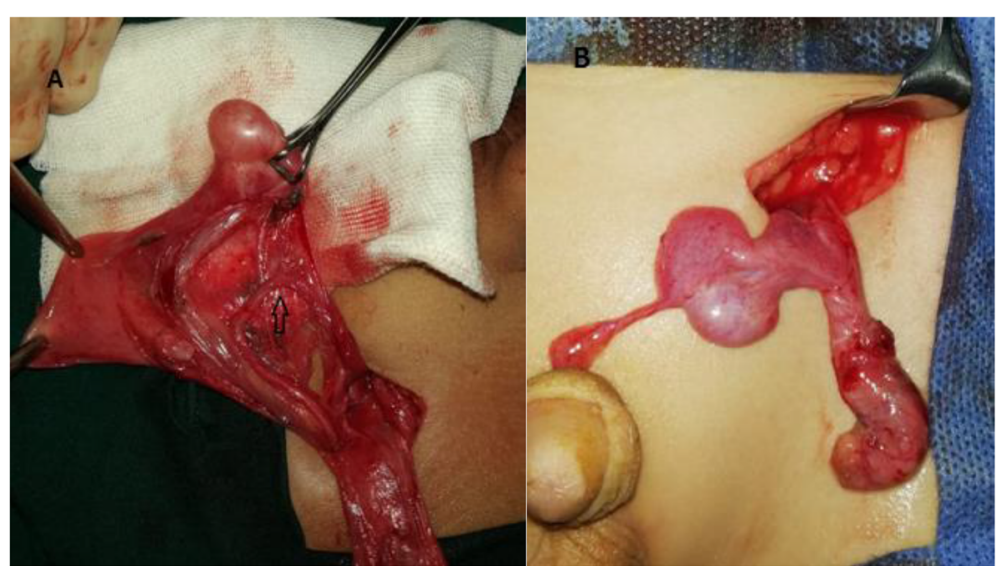

Fig. 3 a Completely separated testis (Babcock forceps) from the epididymis (non-toothed forceps); congenital curled vas deferens (black arrow) is also separated from the tail of the epididymis. b Enlarged stalked epididymal appendix

mesonephric duct, the blood supply to the testicle originates from the internal spermatic artery, while blood supply to the vas deferens originates from the internal iliac artery. During this transition, avascular accident could be responsible for the formation of a segmental epididymis or vas deferens atresia [17]. These three patients of an absent proximal part of the vas deferens were accompanied by ipsilateral testicular agenesis (patients 13, 14, and 15; Figs. 10 and 11, Table 1).

An absent testicle called a vanished or vanishing testis is observed in $3-10 \%$ of cases of cryptorchidism. There are three theories regarding the etiology of congenital agenesis of the testicle: (a) an absence of testicular development during the fetal period; (b) interruption of the vascular supply to the testicle during the fetal period; and (c) atrophy caused by intrauterine testicular torsion [18].

Agenesis of a vas deferens can be suspected based on physical examination. When there is a lack of contralateral ductal anomalies, most men will still be normally fertile. Contralateral anomalies should be suspected when men with unilateral absence of the vas deferens present with subfertility [5]. This anomaly occurs in 0.06 to $1.0 \%$ of healthy men and is more common on the left
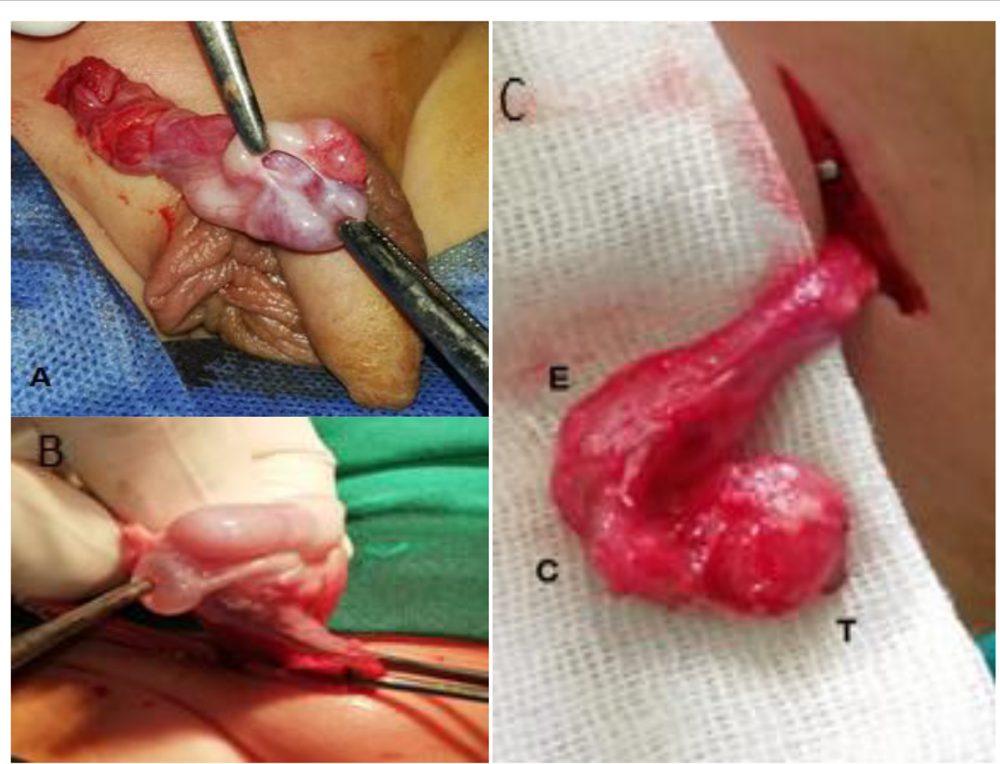

Fig. 4 a Epididymal caput cyst with epididymal body detached from the testis. b Congenital epididymal caput cyst (non-toothed forceps). $\mathbf{c}$ Congenital epididymal corpus cyst 


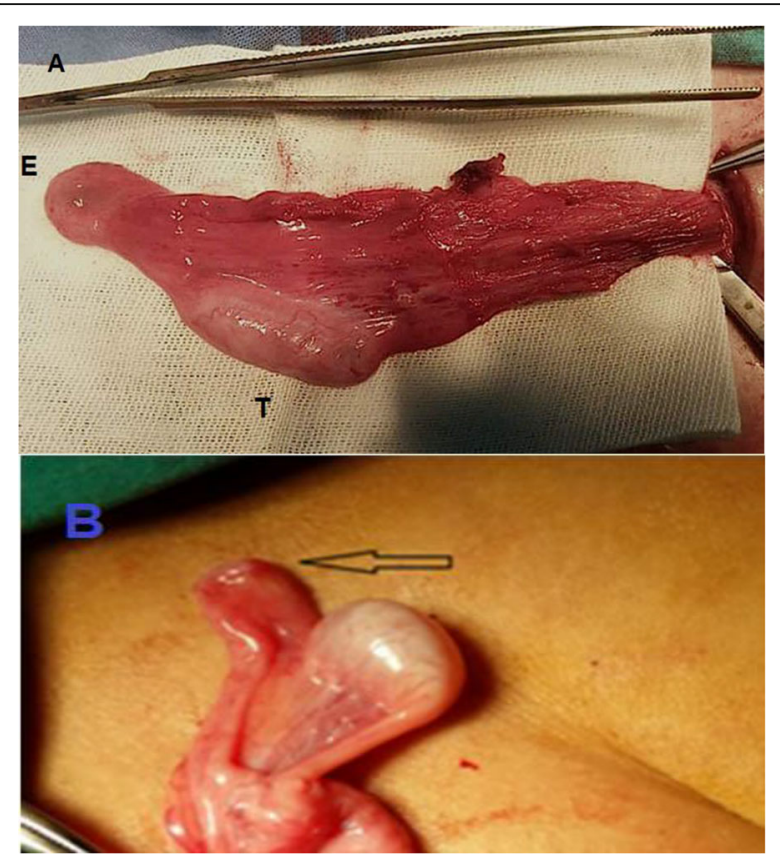

Fig. 5 a A complete separation of testis and epididymis. $\mathbf{b}$ Epididymal head and body detached from the testis

side than on the right. Our three patients with absence vas deferens occurred on the left side (patients 16, 17, and 18; Figs. 12 and 13, Table 1).

In $75 \%$ of patients with unilateral agenesis of the vas deferens, the caput of the epididymis is the only segment present (type C4) [5]. Embryologically, the testicle and epididymal caput emerge from the genital ridge, while the body of the epididymis and the vas deferens originate from the mesonephric tubules and Wolffian duct. Union among these structures occurs via canalization of the rete testis and mesonephric tubules [6].

Patient 19 had a vas deferens that was completely separate from a normal-appearing epididymis and testis Fig. 14. We cannot attribute the congenitally separated vas deferens in this case to a failed union, because the epididymis was completely normal and there was no agenesis in the body or tail of the epididymis. This was the only patient with a congenitally absent ipsilateral kidney. We recommend adding this anomaly and modifying the classification system of the vas deferens.

Patient 12 was unique because he had partial androgen insensitivity syndrome (Fig. 9, malformation type C5). This condition results from insensitivity to the biological actions of androgens in males with normal testicular production of age-appropriate androgen concentrations. This anomaly is caused by mutations in intron 2 of the androgen receptor gene which leads to impaired nuclear translocation after hormone stimulation
[19]. This mutation is found in only $22 \%$ of patients with a partial androgen insensitivity syndrome-like phenotype [20].

Nigel, et al. explained that while androgen resistance can occur in the presence of a normal androgen response (AR), the $A R$ is essential for masculinization. Multiple other components of the AR complex and signaling network are required for complete virilization. There is some evidence supporting the notion that nuclear receptor coregulators play a role in hormone resistance, but the mechanism remains poorly understood [21]. Additionally, this patient had epididymal agenesis, which has been hypothesized to occur as a result of subtle abnormalities in the hypothalamic-pituitary-gonadal axis causing abnormal epididymal development and blunting of the normal postnatal testosterone and gonadotropin surge in boys with cryptorchidism [6]. Complete epididymal agenesis was also not present in the previous classification system, and we have sub-classified this anomaly as type C5.

In addition to the teaching catalog of this paper, this study benefits the scientific community by adding some missing anomalies like enlargement stalk appendix of the epididymis, complete epididymis agenesis,

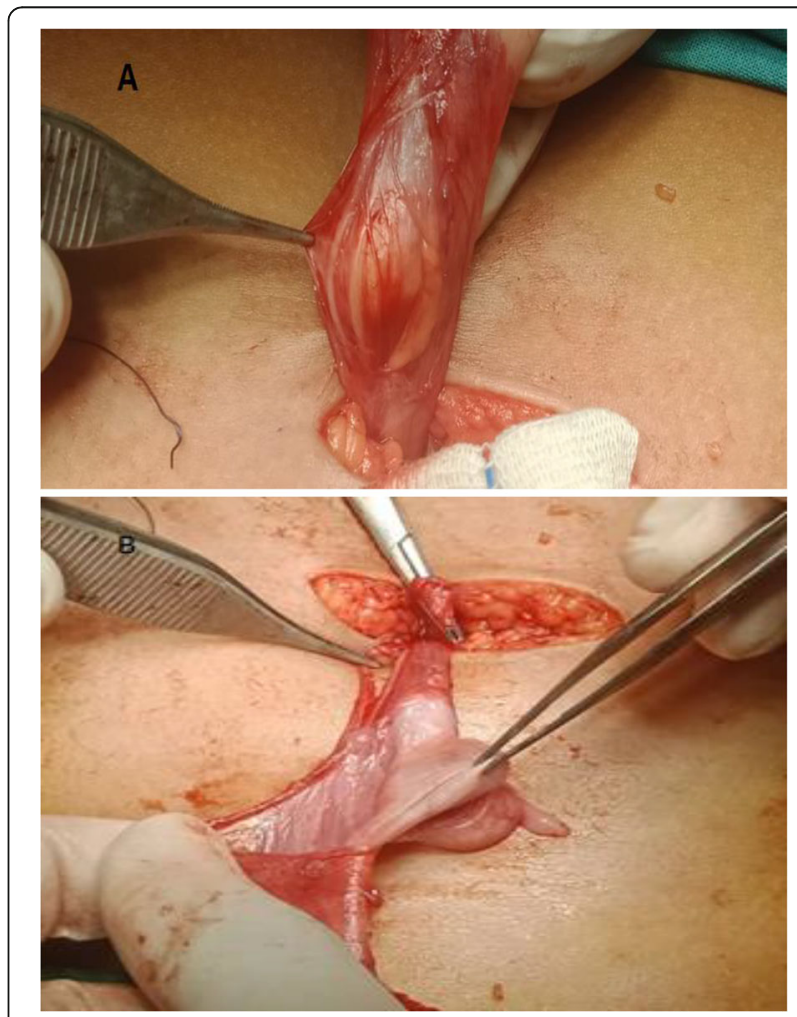

Fig. 6 a Duplication of the vas deferens. b Left epididymis completely separated from the left testis (the upper non-toothed forceps lies between the double vasa deferentia) 


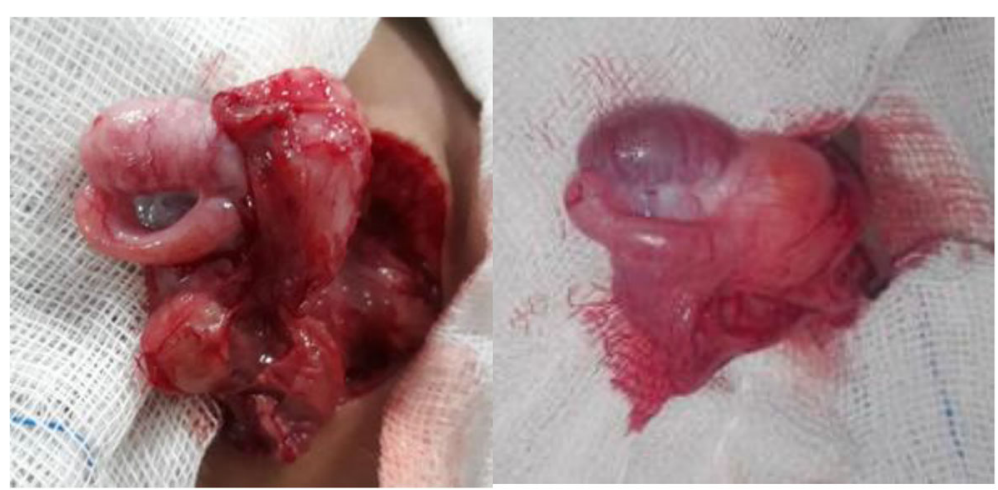

Fig. 7 Two cases with epididymal body detached from the testis

sub-division of an epididymal cyst, and congenital separated vas deferens to the previously existing (classification system) [5].

This study has some limitations. A renal ultrasound was missing in seven included patients due to the absence of a unified protocol for managing these anomalies or incomplete hospital records. Additionally, we did not analyze mutations in the cystic fibrosis transmembrane conductance regulator gene in patients with absent vasa deferentia due to a lack of resources and the absence of a unified protocol.

The availability of intra-operative pictures for our patients depended on the sporadic authors' diligence due to the absence of intra-operative recorders at our institutions, and this resulted in a large number of patients being excluded from the study. Abdelmohsen, et al. published two case reports of congenital anomalies of the vas deferens $[7,8]$. While we used these cases to increase the number of included cases, we did not repeat publication of those pictures. The global rate of vaso-epididymal anomalies in our study is lower compared to the published literature. We attribute our low incidence rate to the poor observation of these anomalies by the surgeon without the benefit of learning modules or pictures.

\section{Conclusion}

Surgeons should be aware of a curled vas deferens or a duplication anomaly when performing orchiopexy. Most of the common anomalies of the vas deferens or epididymis observed in a patient with cryptorchidism occur on the left side. When the proximal part of the vas deferens is missing, the patient usually also has an ipsilateral absent testicle. Vasoepididymal anomalies may be associated with other syndromes. Additionally, we suggest that the classification of vas deferens and epididymal anomalies should be expanded by adding missing anomalies, such as those described here.

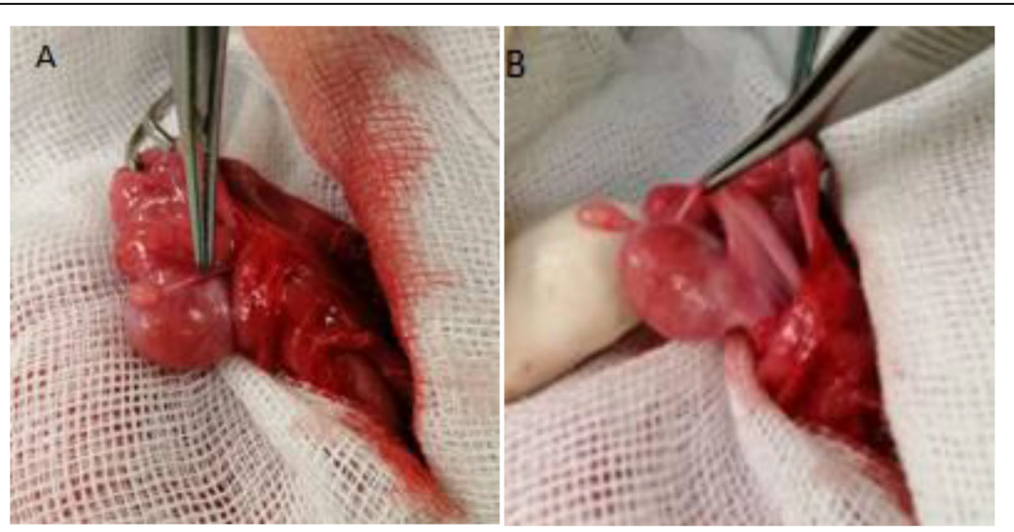

Fig. 8 a Non-toothed forceps demonstrates a congenital diaphragm between the epididymis and testis. b Non-toothed forceps elevates a diaphragm which partially covers this parted body of the epididymis from the testis 


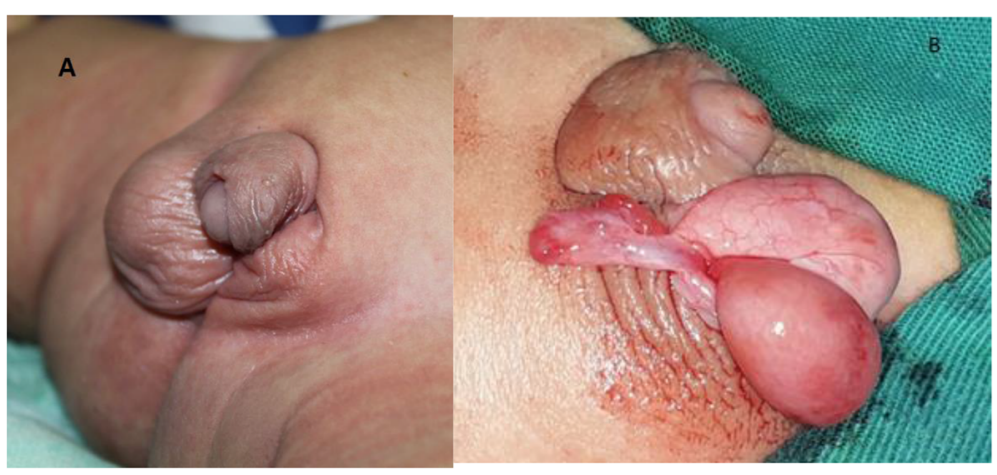

Fig. 9 a Infant with partial androgen insensitivity syndrome: left poorly developed scrotum, hypospadias with ventral chordee, and left palpable undescended testis. $\mathbf{b}$ Complete left epididymal agenesis

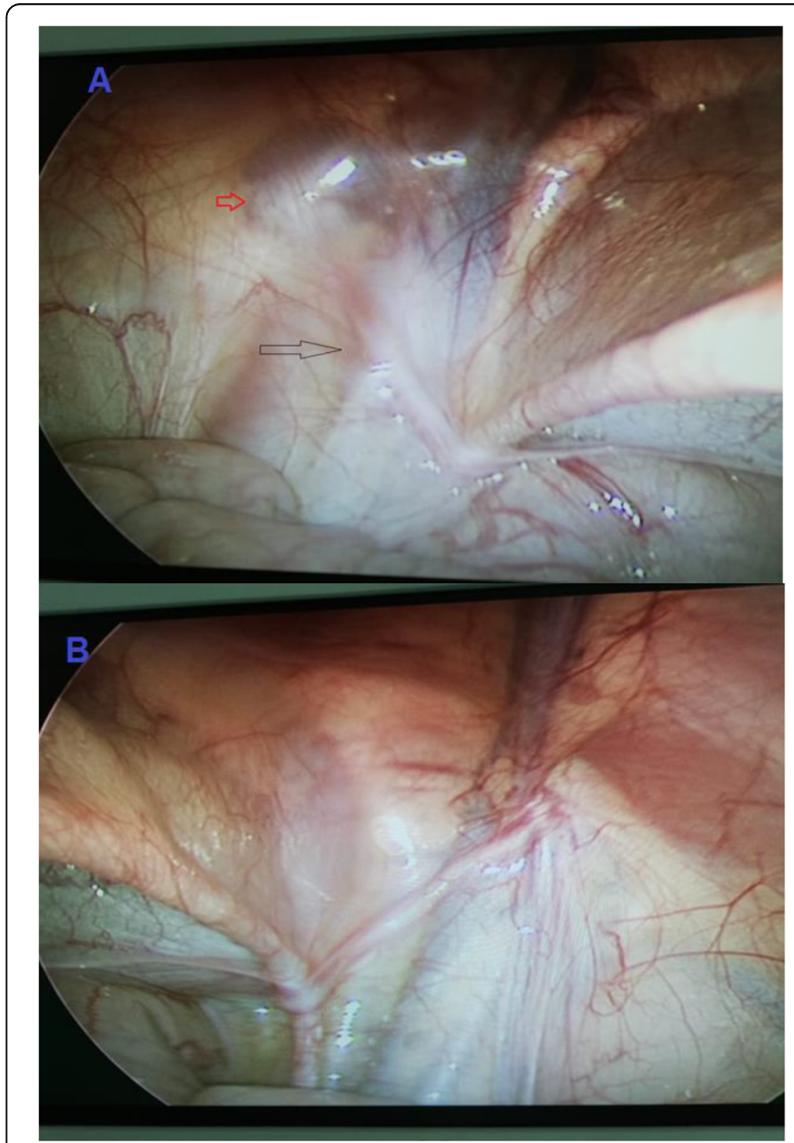

Fig. 10 a Vanished proximal portion of the left vas deferens with absent vessels (black arrow), left closed internal ring (red arrow). b Right side with normal vas deferens and vessels for comparison 


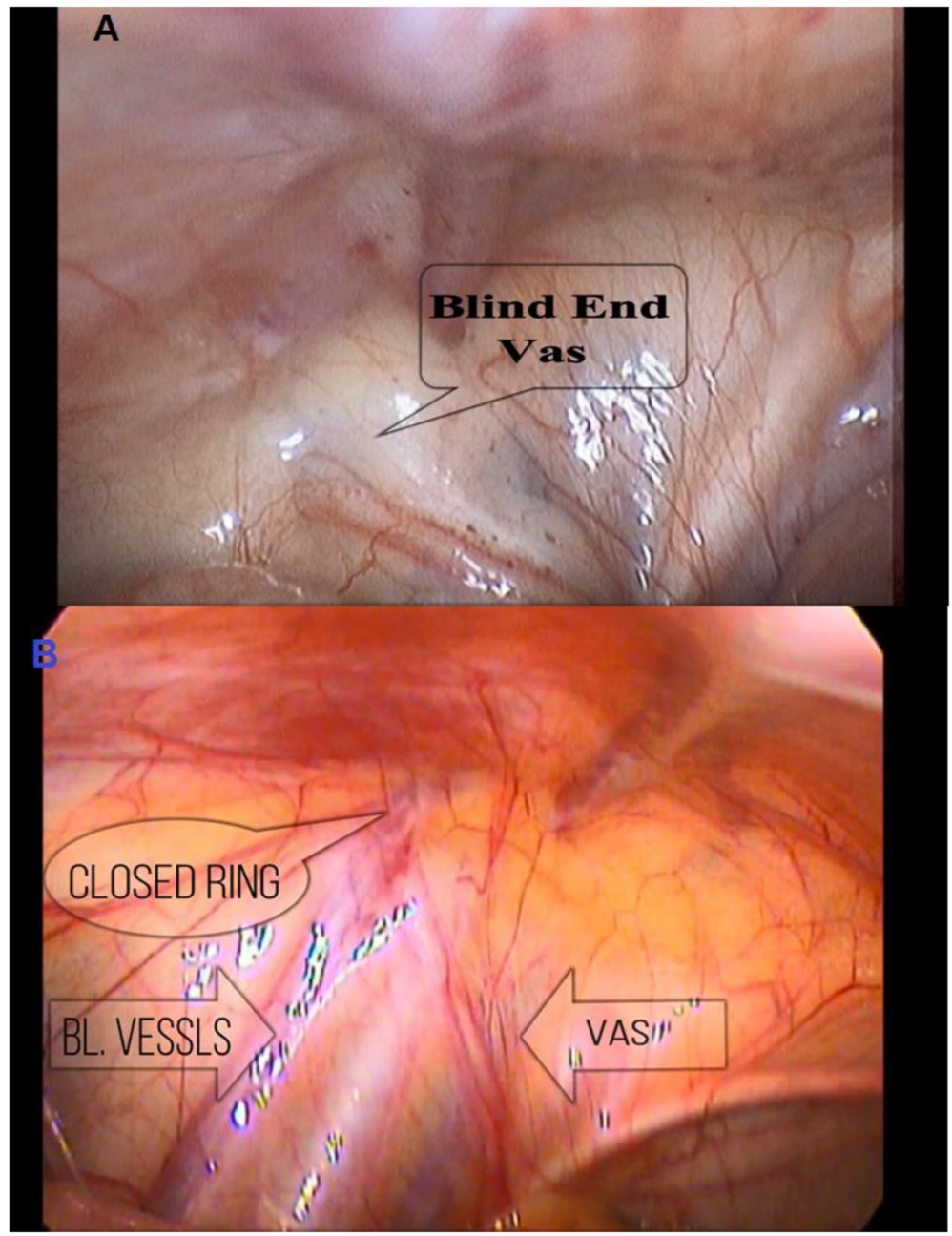

Fig. 11 a, b Vanished proximal portion of the left vas deferens 


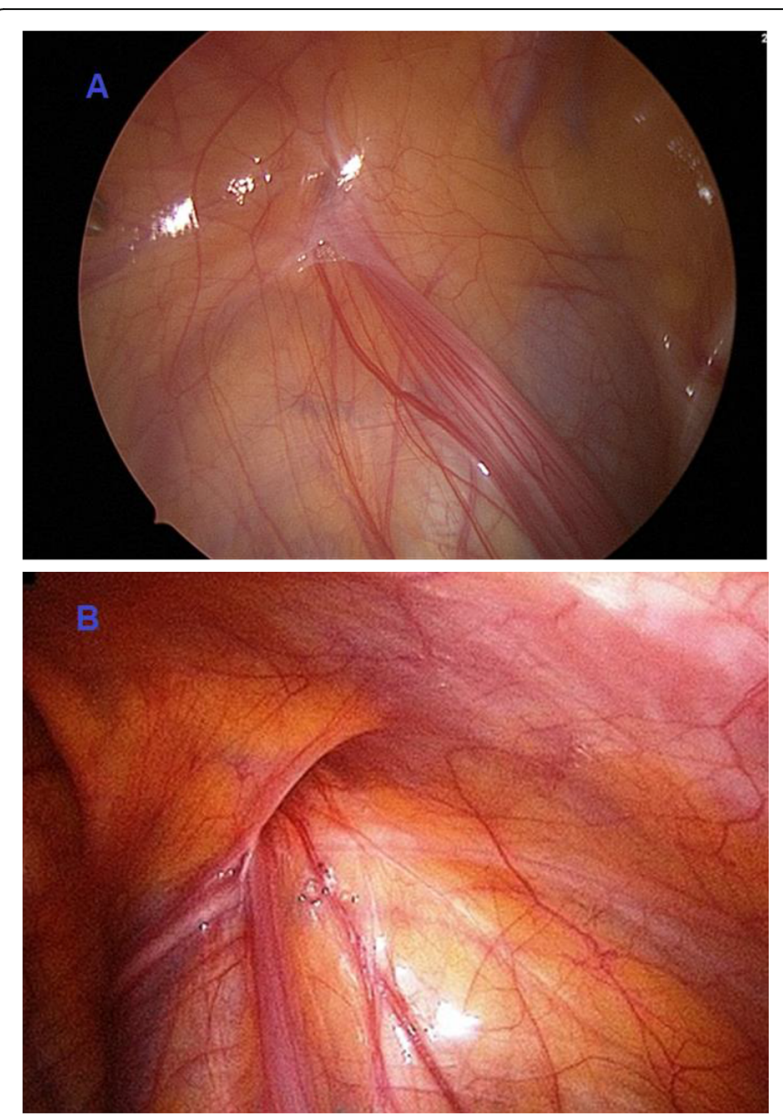

Fig. 12 a Congenital absence of the vas deferens. $\mathbf{b}$ Vas deferens is present on the right side for comparison

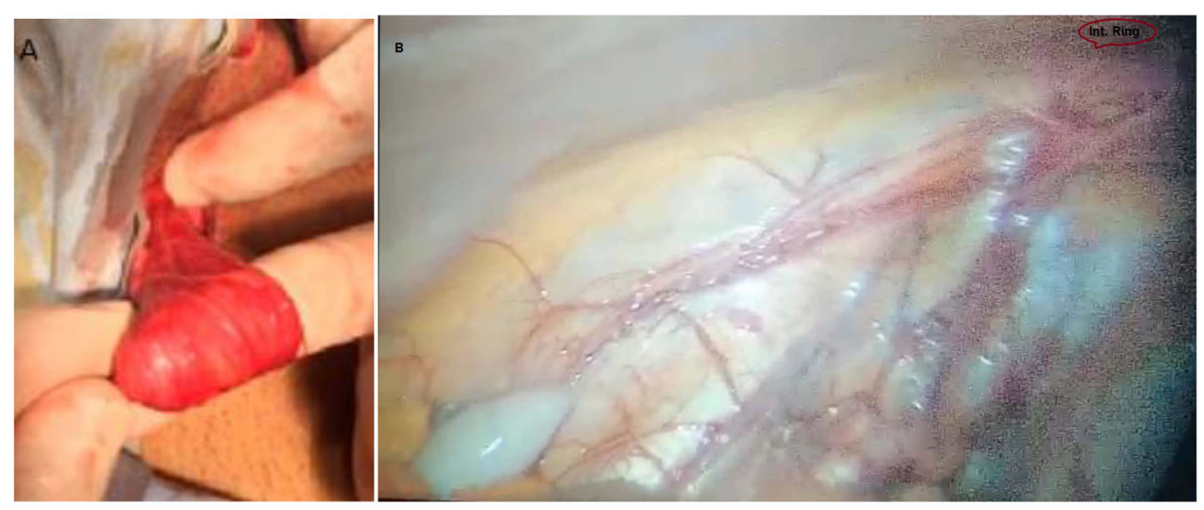

Fig. 13 a Vas deferens agenesis (vessels are present but not the vas deferens). b Congenital absence of the vas deferens 


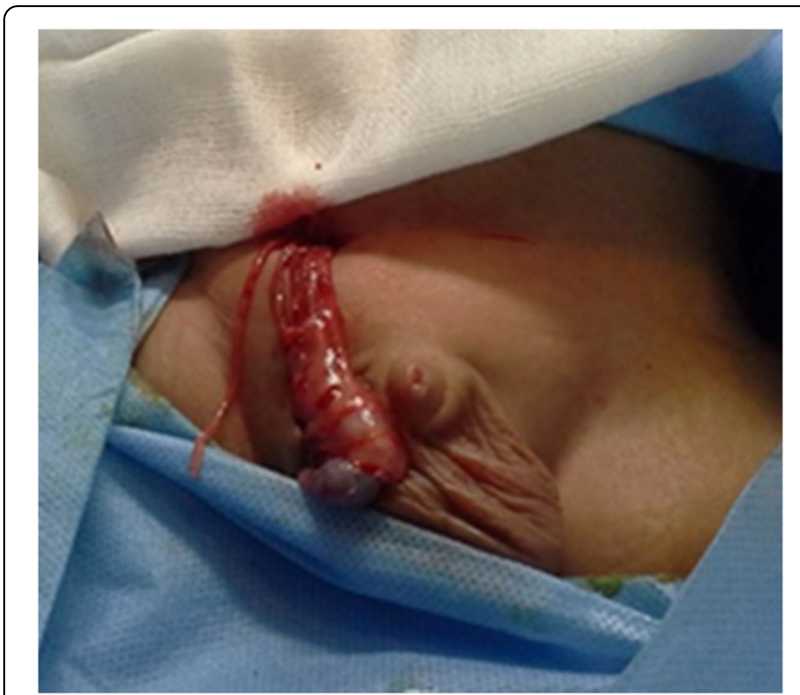

Fig. 14 Congenital separated right vas deferens 


\section{Acknowledgements}

To the 1st, 5th, and 6th scientific papers in the references. They report associated anomalies and classification systems. To our junior doctor at Aswan University Hospital, Mahmoud Rayan. He was an intra-operative assistant in one patient. To Egyptian knowledge bank for free English and grammar correction.

\section{Further information}

This research was discussed at the 3rd international conference for women in science without borders (WISWB) which was held at the British University in Cairo, Egypt, from 12-14 March 2019.

This research was discussed at the Egyptian Society of Surgeon 37th Annual Meeting, 13-15 March 2019 that was held at the Helton Cairo Heliopolis, Egypt.

This research was discussed at the 1st Young Researchers Conference, on 18-20 April 2019 that was held at the Helnan Aswan Hotel, Aswan City, Egypt.

This research was discussed at the EPSA conference that was held in Cairo, 14 of November 2019 as a poster presentation.

\section{Authors' contributions}

$\mathrm{S} \mathrm{A}$ is the pioneer of the work, contributed to the study design, participated in this research by four operated cases, data collection, analysis, interpretation, writing of the paper, and the corresponding author. All other authors participated by different number of operated cases. All authors have read and approved the manuscript.

\section{Funding}

No funding was used to perform this research.

\section{Availability of data and materials}

Available

\section{Declarations}

\section{Ethics approval and consent for participate}

Yes, by Aswan University Hospital Ethical commitment reference no. 526-421. A written informed consent was obtained from the parent and or legal guardian of every participant.

\section{Consent for publication}

A written informed consent was obtained from all of the included patients' parents for operative intervention and for publication of intra-operative pictures.

\section{Competing interests}

The authors declare that they have no competing interests.

\section{Author details \\ ${ }^{1}$ Faculty of Medicine, Pediatric Surgery Unit, Aswan University Hospital, Aswan, Egypt. ${ }^{2}$ Haddaek El Kobba, 27 Diab Fahmiy Str., P.O. Box 11331, Cairo, Egypt. ${ }^{3}$ Faculty of Medicine, Pediatric Surgery Department, Assiut University Hospital, Assiut, Egypt. ${ }^{4}$ Faculty of Medicine, Pediatric Surgery Department, Ain Shams University Hospital, Cairo, Egypt. ${ }^{5}$ Pediatric Surgery Department, Cairo University Specialized Pediatric Hospital, Cairo, Egypt. ${ }^{6}$ Faculty of Medicine, Pediatric Surgery Department, Tanta University Hospital, Tanta, Egypt. ${ }^{7}$ Faculty of Medicine, Pediatric Surgery Department, Al-Azhar University, Cairo, Egypt.}

Received: 28 December 2020 Accepted: 11 June 2021

Published online: 02 November 2021

\section{References}

1. Favorito LA, Javaroni V, Filho JST, Sampaio FJB. Anomalies of the testis, epididymis and vas deferens in normal human fetuses and in patients with cryptorchidism. Brazilian Journal of Urology, Official Journal of the Brazilian Society of Urology. 2000;26(5):530-4.

2. Kroovand RL, Perlmutter AD. Congenital anomalies of the vas deferens and epididymis. In: Kogan SJ, Hafez ESE, editors. Pediatric andrology. The Hague/ Boston/London: Martinus Nijhofl Publishers bv; 1981. p. 173-80. All rights reserved. Copyright $\odot$.
3. Marshall FF, Shermeta DW. Epididymal abnormalities associated with undescended testis. J Urol. 1979;121:341. http://www.ncbi.nlm.nih.gov/ entrez/query.fcgi?cmd=Retrieve\&db=PubMed\&dopt=Abstract\&list_uids=34 733.

4. Scorer CG, Farrington GH. Congenital deformities of the testis and epididymis. New York: Appleton-Century-Crofts. 1971. p. 136. http://scholar. google.com/scholar_lookup?title=Congenital\%20deformities\%20of \%20the\%20testis\%20and\%20epididymis\&author=CG.\%20Scorer\&author= GH.\%20Farrington\&publication_year=1971.

5. Vohra S, Morgentaler A. Congenital anomalies of vas deferens, epididymis and seminal vesicles. Clin Rev ; Urol. 1997;49(3). https://doi.org/10.1016/ S0090-4295(96)00433-5.

6. Han C-H, Kang S. Epididymal anomalies associated with patent processus vaginalis in hydrocele and cryptorchidism. J Korean Med Sci. 2002;17:660-2. https://doi.org/10.3346/jkms.2002.17.5.660.

7. Abdelmohsen SM, Osman MA. Congenital vanished distal part of the right vas deferens, a case report. Urol Case Rep. 2017;15:46-47. Published 2017 Sep 26. https://doi.org/10.1016/j.eucr.2017.09.007. PMID: 28983460; PMCID: PMC5622963.

8. Abdelmohsen SM, Takrouney MH, Osman MA, Abdelmohsen BM. Unique Anomalies of Vas Deferens; A Case Series from Upper Egypt. SM Surg J. 2017;3(2):1013. https://smjournals.com/surgery/fulltext/smsj-v3-1013.php.

9. Moschcowitz AVX. The anatomy and treatment of undescended testis; with especial reference to the Bevan operation. Ann Surg. 1910;52(6):821-35. https://doi.org/10.1097/00000658-191012000-00010.

10. Cundy TP, Goh DW. Beware the looping vas deferens in orchidopexy. Pediatr Case Rep Urol. 2017. @ 2017 Elsevier Inc;104:194-5. https://doi.org/1 0.1016/j.urology.2017.03.022.

11. Kim SO, Na SW, Yu HS, Kwon D. Epididymal anomalies in boys with undescended testis or hydrocele: Significance of testicular location. BMC Urol. 2015;15:108. Published 2015 Oct 24. https://doi.org/10.1186/s12894-01 5-0099-1.

12. Qin KR, Morley C, Nataraja RM, Pacilli M. The spectrum of testicularepididymal fusion anomalies in children with cryptorchidism: Personal experience, systematic review and meta-analysis. J Pediatr Urol. 2020;16(2): 124-9 ISSN 1477-5131.

13. Caterino S, Lorenzon L, Cavallini M, Cavaniglia D, Ferro F. Epididymaltesticular fusion anomalies in cryptorchidism are associated with proximal location of the undescended testis and with a widely patent processus vaginalis. Journal of Anatomy. 2014;225(4):473-8. https://doi.org/10.1111/ joa.12222.

14. Sellars ME, Sidhu PS. Ultrasound appearances of the testicular appendages: pictorial review. Eur Radiol. 2003;13(1):127-35. https://doi.org/10.1007/s0033 0-002-1387-1.

15. Baldisserotto M, de Souza JC, Pertence AP, et al. Color Doppler sonography of normal and torsed testicular appendages in children. AJR Am J Roentgenol. 2005;184(4):1287-92. https://doi.org/10.2214/ajr.184.4.01841287.

16. Posey ZQ, Ahn HJ, Junewick J, Chen JJ, Steinhardt GF. Rate and associations of epididymal cysts on pediatric scrotal ultrasound. J Urol. 2010;184(4 Suppl):1739-42. https://doi.org/10.1016/.juro.2010.03.118.

17. Mollaeian M, Mehrabi V, Elahi B. Significance of epididymal and ductal anomalies associated with undescended testis: study in 652 cases. Urology. 1994;34:6. https://doi.org/10.1016/0090-4295(94)90152-X.

18. Favorito LA, Cardinot TM, Morais ARM, Sampaio FJB. Urogenital anomalies in human male fetuses. Early Hum Dev. 2004;79:41-7. https://doi.org/10.1016/j. earlhumdev.2004.02.004.

19. Wang S, Xia P, Cacalano NA, Xu H, Li D. Complete androgen insensitivity syndrome caused by c.1769-1G > C mutation and activation of a cryptic splice acceptor site in the androgen receptor gene. Steroids. 2018;137:64-9. https://doi.org/10.1016/j.steroids.2018.05.012.

20. Lek N, Miles H, Bunch T, Pilfold-Wilkie V, Tadokoro-Cuccaro R, Davies J, et al. Low frequency of androgen receptor genemutations in 46XY DSD, and fetal growth restriction. Arch Dis Child. 2014;99(4):358-61. https://doi.org/10.113 6/archdischild-2013-305338.

21. Mongan NP, Tadokoro-Cuccaro R, Bunch T, Hughes IA. Androgen insensitivity syndrome. Best Pract Res Clin Endocrinol Metab, ISSN: 18781594. 2015;29(4):569-80. https://doi.org/10.1016/j.beem.2015.04.005.

\section{Publisher's Note}

Springer Nature remains neutral with regard to jurisdictional claims in published maps and institutional affiliations. 